\title{
SEVERAL IMPORTANT ISSUES FROM FIELD AND MODEL INVESTIGATIONS ON LANDSLIDES
}

\author{
Masaharu FUJITA ${ }^{1}$ and Daizo TSUTSUMI ${ }^{2}$ \\ ${ }^{1}$ Member of JSCE, Dr. of Eng., Professor, Disaster Prevention Research Institute, Kyoto University \\ (Yokoohji, Fushimi-ku, Kyoto 612-8235, Japan) \\ ${ }^{2}$ Member of JSCE, Dr. of Agri., Associate Professor, Disaster Prevention Research Institute, Kyoto University \\ (Nakao, Okuhida-onsengo, Takayama 506-1422, Japan)
}

\begin{abstract}
The landslides due to heavy rainfalls have been thoroughly investigated by many researchers to mitigate the sediment disasters. However, because of the complicated mechanism of the landslide, it is difficult to predict the landslide accurately by the conventional simulation method. Of course there are many factors such as the rainfall, surface and subsurface geomorphology, and soil physical properties affecting the occurrence, but it is very significant to point out the important issues on landslides for the future research. Last five years, authors have investigated several landslides in Japan, and examined the landslide occurrence by experimental and modeling approaches. Consequently, some important issues which have a great influence on the landslide occurrence were found. In this paper, these issues are reported.
\end{abstract}

Key Words : Landslides, sediment disasters, preferential flow, multi-phased landslides

\section{INTRODUCTION}

Every year, we have sediment disasters during rainy or typhoon season. Landslides are one of the most typical phenomena causing the disasters. As it is predicted that strong storms increase with the global climate change, it is likely that huge sediment disasters could occur frequently in near future. Many researchers have tried to develop the prediction models on landslide, but we have not obtained any models with a high precision. It is important to find out the essential points affecting landslides through field investigation and adopt them into the models. Authors visited some sites of landslides and try to connect the findings with the prediction. Table $\mathbf{1}$ is a list of the landslides which the authors investigated. By these investigations, authors confirmed the following important issues:

1) Influence of subsurface geomorphology such as preferential flow pathways and bedrock topography on landslide

2) Multi-phased landslide process

3) Influence of rainfall patterns on landslide

In the following sections, each issue is discussed in detail with the results of field investigation, rainwater infiltration analysis and slope stability analysis. The rainwater infiltration analysis was conducted solving Richard's equation with the finite element method ${ }^{1), 2}$. Simplified Janbu method applicable to unrestricted shape of slip-surface was employed for the slope stability analysis, and the dynamic programming method was combined to determine the critical slip-surface. Detail of the simulation method is provided in a reference ${ }^{3)}$.

Table 1 List of the landslides which the authors investigated

\begin{tabular}{c|l|l|}
\hline Date & \multicolumn{1}{|c|}{ Location } & \multicolumn{1}{c|}{ Remarks } \\
\hline 20/07/2003 & Minamata, Kumamoto Pref. & Local rainstorm \\
01/08/2004 & Kisawa, Tokushima Pref. & Typhoon 0410 \\
29/09/2004 & Miyagawa, Mie Pref. & Typhoon 0421 \\
06/09/2005 & Taketa, Oita Pref. & Typhoon 0514 \\
\hline
\end{tabular}

\section{SUBSURFACE GEOMORPHOLOGY}

The preferential flow pathways within the soil layer generally hasten rainwater infiltration and make the slope stable. However, it has been repeatedly pointed out that the preferential flow clogging decreases the slope stability and some times triggers the landslide ${ }^{4)}$. Similar phenomenon is also true for the preferential flow through fractures within bedrock. As an example, a landslide occurred in Minamata, Kumamoto Prefecture, in 2003 is 
introduced herein. The investigation result on the landslide revealed that the weathered andesite layer on the tuff-breccia bedrock contained many fractures. This landslide is moderately deep (maximum depth was 10-15 m). It occurred during the highest rainfall intensity although generally such a deep landslide occurs late after the peak rainfall. Probable scenario of this landslide process is that rapid rainwater transportation through the fractures of the weathered andesite quickly developed pore water pressure at the bottom of weathered andesite layer, and the relatively deep sheeted landslide occurred without a delay from the rainfall peak time ${ }^{5)}$. To confirm this scenario, numerical simulation on rainwater infiltration and subsequent slope stability changing process were conducted. Soil layer was assumed $2 \mathrm{~m}$ in depth from the surface, and weathered andesite layer was laid below it. No flux boundary condition was imposed on the bottom of the weathered andesite layer. Three cases of the preferential flow pathways were assumed in the calculation as shown in Fig.1. In Case 1, there is no preferential flow pathway. In Case 2, three lateral soil pipes (diameter $=5.0 \mathrm{~cm}$ ) were placed at a boundary between the soil and weathered andesite layers, and these pipes were connected to the vertical fractures whose shape was approximated to that of the soil pipes. These vertical fractures were connected to a lateral fracture near the bottom of weathered andesite layer, whose outlet was opening to the outside of the slope at the down-slope end. In Case 3, similar preferential flow pathways to the Case 2 were assumed but the lateral fracture near the bottom of the weathered andesite layer was discontinuously broken into three lateral fractures, and downstream end of those lateral fractures were remained inside of the weathered andesite layer. All preferential flow pathways were set on a vertical plane placed on the center of the slope width (2m). Fig.2 shows the hyetograph given for the simulation and calculated the changes of the safety factor. In Case 1, the safety factor decreases lower than 1.0 at the beginning of rainfall peak. This means the occurrence time is too early than the real landslide. In Case 2, the safety factor keeps high level and does not decrease lower than 1.0. In Case 3 , the safety factor decreases suddenly at the beginning of rainfall, and decreases lower than 1.0 at the end of rainfall peak. Therefore, to simulate the rainwater infiltration and slope stability accurately, it is very important to include the preferential flow pathways within the soil or bedrock layers.

\section{MULTI-PHASED LANDSLIDES}

\section{(1) Field investigation}

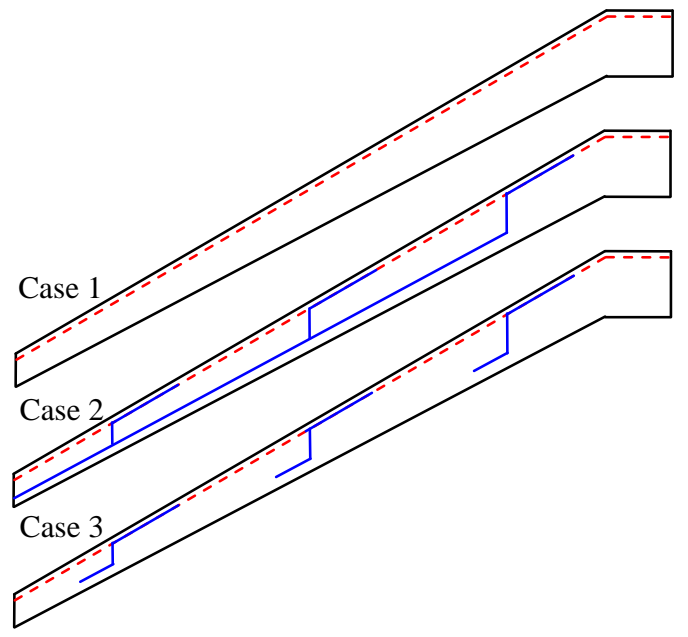

Fig. 1 Different three cases of the preferential flow pathways

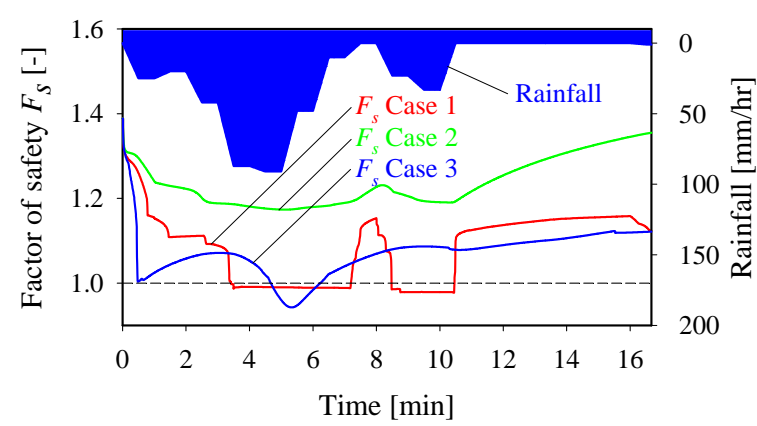

Fig. 2 Hyetograph given for the simulation and the changes of the safety factor for each case

Photo 1 shows a landslide in Kotaki area, Miyagawa, Mie Prefecture, in 2004. On the site after the landslide occurrence, the collapse seemed to occur at the top of the slope. However, according to an interview with a resident who witnessed the landslide, first collapse occurred around the middle part of the slope, and about 20 min later the upper part of the slope was collapsed. Also in the field investigation of a landslide in Minamikochi area, Taketa, Oita Prefecture, in 2005 and in Kashu area, Kisawa Villege, Tokushima Prefecture, in 2004 it was found that such a multi-phased landslide occurred. These landslides tell us that multi-phased landslides are not unusual phenomenon and the investigation of the process is very important not only to elucidate the mechanism but also to prevent the secondary disaster.

\section{(2) Experiment}

The experiment was conducted in Ujigawa Open Laboratory, Disaster Prevention Research Institute, Kyoto University. The objective of this experiment is to investigate how the landslide is affected by the physical properties of the soil. Three kinds of soils with different internal friction angle $\phi$, cohesion $c$ and permeability $k$ were prepared for the experiment. The soil consisting of silica sand and pearl clay used in Case 1 has coherent of $0.054 \mathrm{tf} / \mathrm{m}^{2}$ 
and repose angle of 25 degree and permeability of $0.050 \mathrm{~cm} / \mathrm{s}$. In Case 2, the coherent, the repose angle and the permeability are $0 \mathrm{tf} / \mathrm{m}^{2}, 37$ degree and 0.567 $\mathrm{cm} / \mathrm{s}$. In Case 3, the coherent, the repose angle and the permeability are $0 \mathrm{tf} / \mathrm{m}^{2}, 37$ degree and $0.079 \mathrm{~cm} / \mathrm{s}$. The soil slopes in Case 1 and Case 2 are sustained by the cohesion and the friction, respectively. The soil in Case 2 has a high permeability. The soil was filled in the flume with $5.0 \mathrm{~m}$ in length, $0.2 \mathrm{~m}$ in width, $0.3 \mathrm{~m}$ in depth, and 30 degree gradient for each case. On the soil surface, artificial rainfall with intensity of $150 \mathrm{~mm} / \mathrm{hr}$ was supplied.

As a result, the landslides were occurred in Cases 1 and 3, but not in Case 2 because of high permeability of the soil. The landslide was occurred 15'05" from the beginning of the rainfall for the Case 1, and 13'13" from the beginning of the rainfall. As shown in Fig.3, large portion of the slope was collapsed at one time in Case 1 . On the other hand, three divided portion of the slope were collapsed one by one, with an interval of $0.4 \mathrm{~s}$ in Case 3 . The measured pressure potential indicated that the underground water table almost reached to the surface and saturated area widely spread out the whole soil layer in Case 1, but the slope held out. When a critical stage for collapse reached, whole slope became unstable and the large landslide occurred. In Case 3, the underground water table developed close to the down-slope end, and the saturated area was restricted in the soil layer of the lower part of the slope. Then, the lower part of the slope became unstable and small landslide near the down-slope end occurred because the cohesion is very small. The upper part of the slope lost the support after the first collapse, and then second and third collapses were occurred one after another. This result shows that a long collapse occurs in the slope sustained by cohesion and a short collapse occurs in the slope sustained by friction. Therefore, the occurrences of the single landslide and multi-phased landslide might depend on the soil physical properties.

\section{(3) Effect of soil physical properties on landslide size and timing}

To know the effect of each physical property on multi-phased landslides, simulations were conducted for several different sized hypothetical slopes, applying various internal friction angle $\phi$, cohesion $c$, and permeability $K_{s}$. Fig.4 is a diagram indicating the effect of the soil strength on the size of the first landslide obtained by the simulation. The slope for the simulation, soil hydraulic properties, and rainfall condition were assumed to be those in the experiment. Red and blue triangles in the diagrams are the areas where the slope collapses at

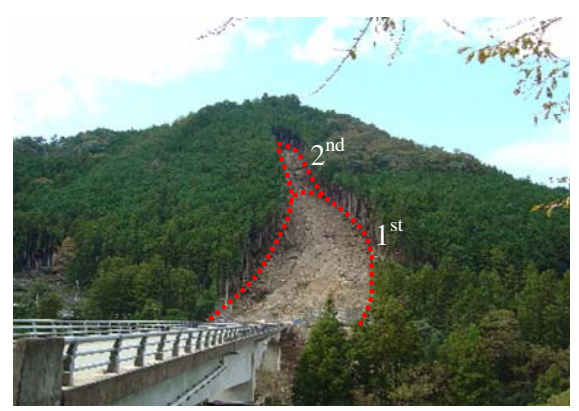

Photo 1 Multi-phased landslide occurred in Kotaki area, Miyagawa, Mie Prefecture, 2004

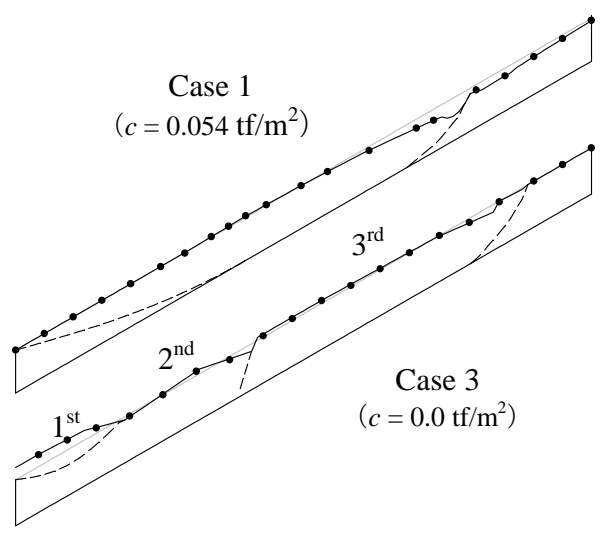

Fig.3 The observed shape of the slip surface for the experimental Case 1 and 3
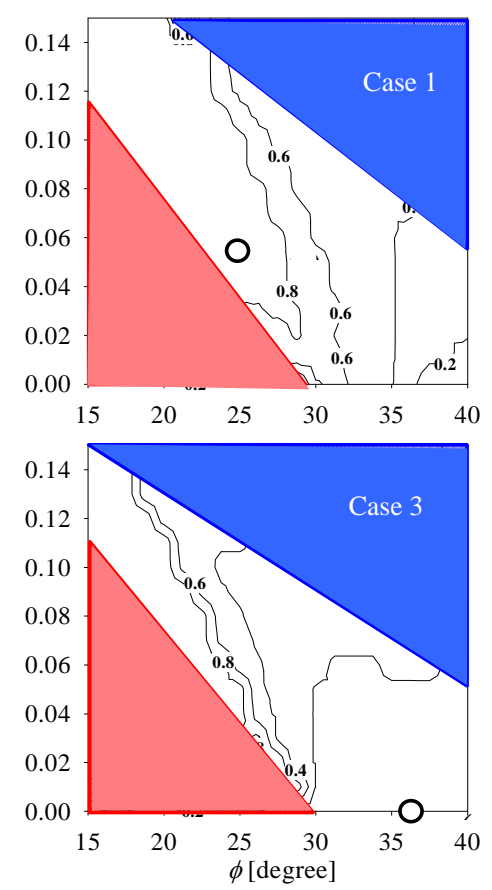

Fig.4 Effect of the soil strength on the size of landslide obtained by the simulation.

the initial stage of the simulation and the slope does not collapse at the equilibrium state, respectively. The circles indicate the results of the experiment. Fig.4 indicates that the size of collapses tends to increase as the soil cohesion $c$ increases and internal friction angle $\phi$ decreases in both Cases 1 and 3 . 
This tendency indicates that a large part of the slope collapses in one time if the soil has large $c$ and small $\phi$, and the multi-phased landslide tends to occur if soil has small $c$ and large $\phi$. Comparing the simulation and experiment results, actual size of the first collapse does not agree perfectly, but the simulated diagram shows the different tendency between Case 1 and 3 very well.

\section{RAINFALL PATTERNS}

In Senokuchi area, Taketa, Oita Prefecture, a deep sheeted landslide occurred due to over $500 \mathrm{~mm}$ total precipitation by typhoon 0514, in 2005. The maximum rainfall intensity was not so high (about $30 \mathrm{~mm} / \mathrm{hr}$ ), but the duration of the rainfall was more than 48 hours ${ }^{3}$. To elucidate the effect of rainfall characteristics such as the intensity and duration on the landslide, we conducted the rainwater infiltration analysis and slope stability analysis applying the actually measured rainfall and three different hypothetic rainfall data. Fig.5 shows four rainfall events which were applied in the simulation. Case 1 is the actually measured rainfall. Case 2 is the hypothetic rainfall with intensity twice and duration half as mach as Case 1, and Case 3 is the hypothetic rainfall with intensity four times and duration $1 / 4$ as much as Case 1 . Case 4 is the hypothetic rainfall with intensity half and duration twice as much as Case 1. Hence, although the intensity and duration are different each other, all cases have the identical total precipitation.

The results were shown in Fig.5. Upper figure shows the changes of the rainfall intensity and the safety factor $F_{s}$, and lower figure shows the calculated shape of the slip surface. The safety factor $F_{s}$ decreases as the rainfall increases in every case. However, its sensitivity on rainfall differs depending on the rainfall pattern. Actually, the delays from rainfall peak to landslide occurrence are 192, 32 and $10 \mathrm{~min}$ for Case 1, 2 and 3, respectively. Comparing the shape of slip surface for each case, the size of the landslide becomes larger as the longer duration and lower intensity of rainfall. These tendencies of timing and size of the landslide depending on the rainfall pattern agree well with empirically obtained relationship between landslide and rainfall. The rainfall with the longest duration and lowest intensity (Case 4) did not cause a landslide. Therefore, the threshold rainfall intensity which can cause landslide may exist for each slope depending on the topography and

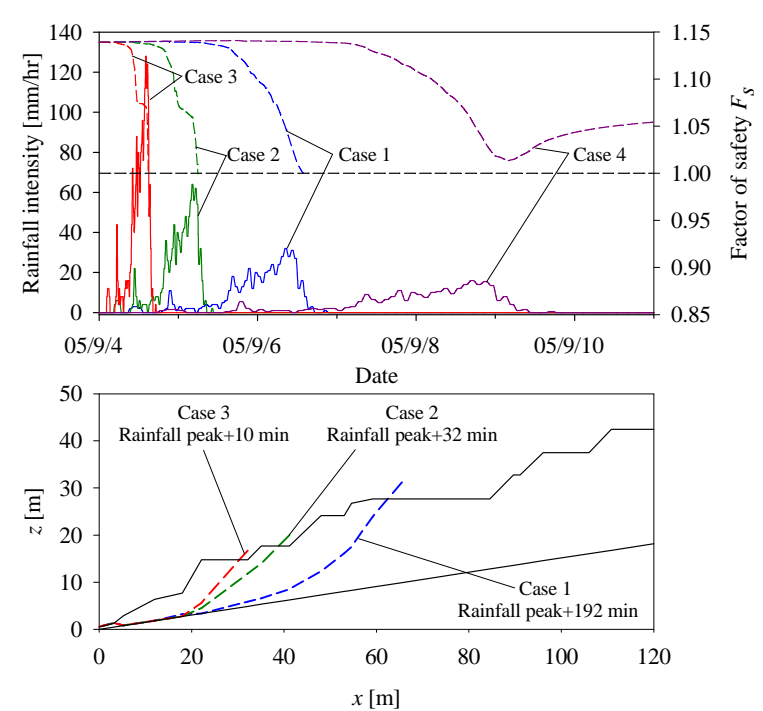

Fig.5 Changes of rainfall intensity and simulated factor of safety and calculated shape of slip surface for each rainfall pattern

hydraulic properties of soil layer.

\section{CONCLUSIONS}

Through the field and model investigations on four landslide disasters, several important issues to understand the mechanism of landslide occurrence and mitigate the landslide disaster, were found out. As a result, to elucidate mechanism of the landslide and to mitigate the landslide disaster, it is necessary to improve the landslide prediction method by including the complicated factors such as the subsurface geomorphology, multi-phased landslide occurrence, and rainfall characteristic.

\section{REFERENCES}

1) Istok, J.: Groundwater Modeling by the Finite Element Method, American Geophysical Union, Washington DC, 495, 1989

2) Zienkiewicz, O. C.: The finite element method in engineering science, McGraw-Hill, Berkshire, England, 1971

3) Tsutsumi, D., Fujita, M. and Hayashi, Y.: Numerical simulation on a landslide due to typhoon 0514 in Taketa City, Oita Prefecture, Annual Journal of Hydraulic Engineering, Vol. 51, pp.931-936, 2007 (in Japanese)

4) Pierson, T. C.: Soil pipes and slope stability, Quarterly Journal of Engineering Geology, 16, pp.1-11, 1983

5) Sidle, R. C. and Chigira, M.: Landslides and debris flows strike Kyushu, Japan, EOS transactions AGU, 85 (15), pp.145, 15, 2004

(Received January 31, 2008) 